\title{
9 THE ARCHAISM AND LINGUISTIC CONNECTIONS OF SOME YIR-YORONT TRACT-NAMES
}

\author{
Barry Alpher
}

\section{PEOPLE, COUNTRIES AND LANGUAGES ${ }^{1}$}

Yir-Yoront (pronounced Yirr-Yorront) ${ }^{2}$ speakers' country lies around the mouths of the Mitchell River in western Cape York Peninsula, Queensland. Their land tenure is organised in terms of named tracts, many of considerably less than a kilometre in breadth. ${ }^{3}$ Sets of tracts, usually but not always contiguous within the territory of the Yir-Yoront language, make up the estate of a patrilineal clan (Sharp 1934a and b; in more recent and exact terminology, a group in which membership is assigned through serial patrifiliation; see Sutton 1998:24). Some of these clans are represented among speakers of other languages and in territory other than that of Yir-Yoront (Sharp 1958), but Yir-Yoront appears in all recorded sources and, from information obtained currently, to have been spoken within a contiguous territory within which only one very small enclave is recognised as the territory of speakers of another language.

Acknowledgements: I thank Jane Simpson for editorial advice on content, and I thank the Australian Research Council for its support (Grant 'Analysing Australian Aboriginal Languages', administered through the University of Melbourne Department of Linguistics and Applied Linguistics) of the fieldwork (19972000) during which I recorded the Yirrk-Mel placenames I report on here.

2 Yir-Yoront has stops $p, t h, t, r t, c h, k$, and $q$ (glottal stop), nasals $m, n h, n, m, n y, n g$; liquids $l, l h$, $r r$; glides $w, r, y$; vowels $i, e, a, o, u$, and $v$ (shwa). Compounds with a hyphen written in the middle have an unstressed first part and a primary-stressed second. Compounds with primary stress on the first part and secondary on the second are written with a plus sign in the middle (in the text; on the map they are written with both parts capitalised and no space in between: $K a w n Y u m l h)$. I have also written ' + ' to separate inflection material from stems where the analysis is relevant. In this paper I am using the same symbols (less glottal stop) and conventions to represent examples from neighbouring languages, despite variations in the sound systems. Simplex words in Yirrk-Mel always stress the second full vowel (not shwa), but stress is unpredictable in Kokapér as written here and is indicated with an acute accent. Kokapér initial (and after a nasal in a monosyllable) $/ t /$ is frequently realised as [trr], an apical voiceless stop with voiced trill release; by convention I have written Trvpénvmvn and Tarrch-Manéngk, although the latter in particular is often heard with [trr].

3 See in this connection Sinnamon and Taylor (1978), who show the tract-like rather than point-like nature of most (not all) sites in this area.

L. Hercus, F. Hodges and J. Simpson, eds, The Land is a Map: placenames of Indigenotis origin in Australia, 131-139. Canberra: Pandanus Books in association with Pacific Linguistics, 2002.

(c) Barry Alpher 


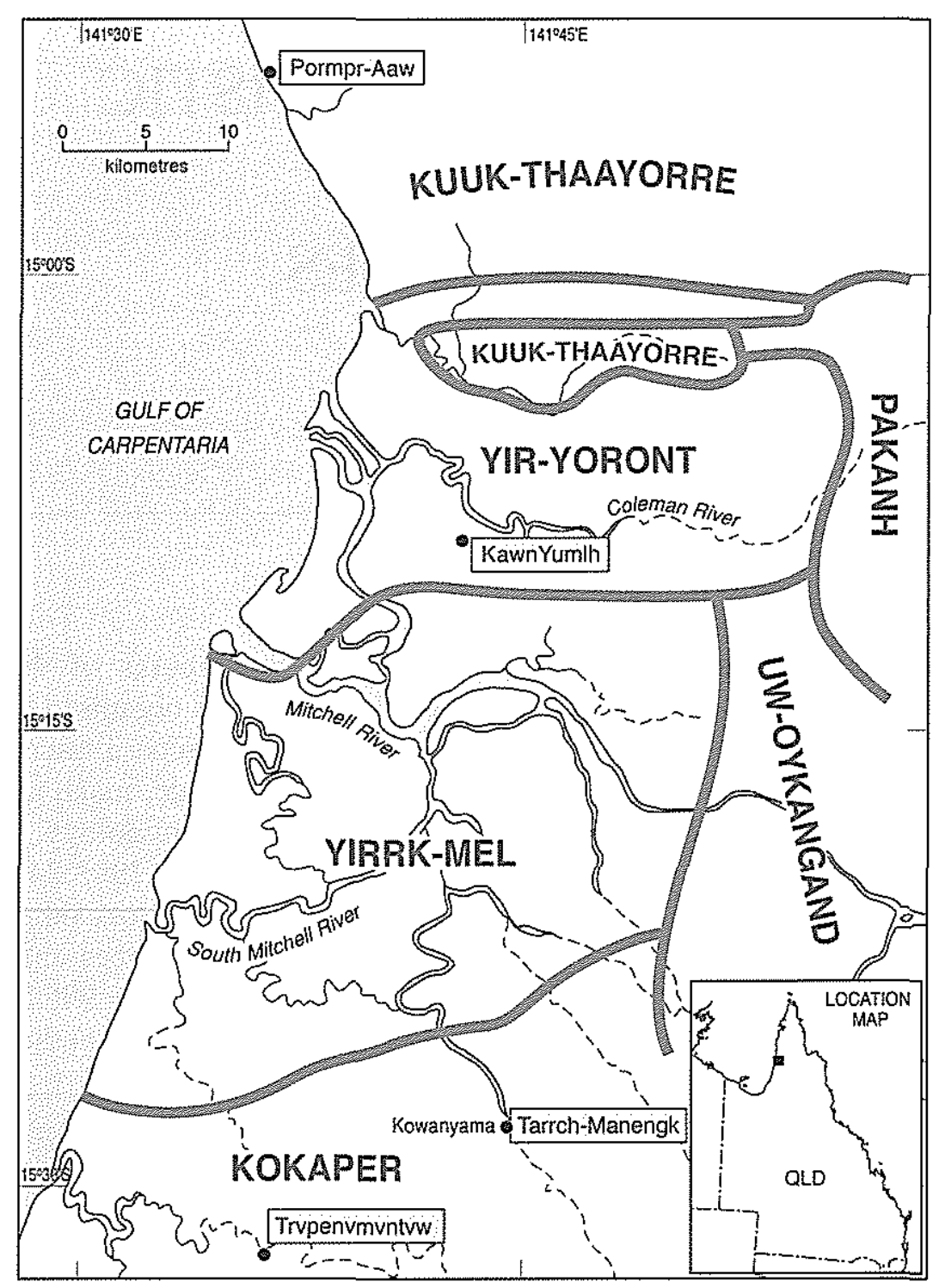

Map 1: Major places and language areas mentioned in the text. Language boundaries are those reported for the 1930s (Sharp 1937) and are schematic only. Sample Indigenous names (those shown on other publicly available maps, and that of the Kowanyama location) are enclosed in rectangles; their locations as shown are approximate only.

South of Yir-Yoront are the territories of its sister-dialect (or sister-language) Yirrk-Mel (Yirrk-Thangalkl, in Yir-Yoront called Yirr-Thangell [thángedl]) and of the closely related Kokapér; ${ }^{4}$ north of Yir-Yoront is the territory of the closely related Kuuk-Thaayorre; and to its north-east that of the less closely related Pakanh. Much of the south-eastern part of Yir-Yoront territory was Yirrk-Mel-speaking in the not-too-distant past, and Map 1 reflects the situation as of $1934 . .^{5}$ In this study I draw on corpora of properly transcribed placenames

4 This language name is also spelt Koko-Bera, Koko-Pera and Kok-Kaper. I use here the transcription currently favoured by Paul Black, who is preparing a description in depth.

5 Land-tenure maps of parts of Yir-Yoront and Yirrk-Mel territory can be found in Sharp (1937) and Sinnamon and Taylor (1978). 
numbering roughly 100 for Yir-Yoront, roughly 50 for Yirrk-Mel, and rather fewer for Kuuk-Thaayorre and Kokapér.

\section{THE INTERNATIONAL NATURE AND COGNATION OF SOME OF THE PLACENAMES}

Each of these languages has names for tracts in the territories of the others, but the names are not simple duplicates. Often these names are direct translations of the foreign names: ${ }^{6} \mathrm{Kuuk}$ Thaayorre Pormpvr-Aaw (the contemporary settlement Pormpuraaw, formerly Edward River Mission) and Yir-Yoront Ngolt-Thaw name the same place and both mean 'door'. The KuukThaayorre form consists of pormpvr 'house' and aaw 'mouth'; the Yir-Yoront form consists of ngolt 'house' and thaw 'mouth'. In some cases, the elements of a placename in two or more languages not only translate each other but appear to be cognate: they continue a single form, affected only by sound-change, from the language ancestral to the modern languages. In the case of the name Pormpvr-Aaw/Ngolt-Thaw, the second element is cognate in KuukThaayorre and Yir-Yoront, continuing a form *tjaawa from Proto- Paman. ${ }^{7}$ Other examples of partially or wholly cognate tract-names follow:

(1) The Kokapér site Trvpénvmvntvw (Trubanaman, the original site of Mitchell River Mission in 1904), also named by Yir-Yoront Lipalh; both mean 'termite-mound'; each contains a suffix (the suffixes are non-cognate); the stems preceding the suffixes, tvpen in Kokapér and lipn in Yir-Yoront, are cognate and continue Proto Paman *tipan.

(2) The Kokapér site Tarrch-Mvnéngk, also named by Yirrk-Mel Tarrch-Mono and Yir-Yoront Larry-Munu (also Larry-Monql); ${ }^{8}$ all mean 'Morinda citrifolia fruit [stuck] in the throat'; the first element of each designates the fruit and continues ancestral (local) *taarrtja, and the second means 'in the throat' and continues ancestral *manungku.

(3) The Yirrk-Mel site Thetethrr-Thak, also named by Yir-Yoront Therteyrr-Tha; the first element means 'sandpaper fig'; both elements correspond regularly.

6 I avoid the term 'loan-translation' here because at least some of the time these pairs of names are references to commonly held mythic material not necessarily having priority in the language proper to the named place.

7 The forms that I am calling 'ancestral' are drawn from the set reconstructed by Hale $(1964,1976 \mathrm{a}, \mathrm{b}, \mathrm{c})$ and augmented by myself, for the protolanguage called 'Proto Paman' postulated as ancestral to the contemporary languages of the Peninsula region. Regularly corresponding cognate sets, for which a reconstruction (a putative ancestral form) is possible but which cannot be said to have belonged to Proto Paman or any identifiable subgroup, I designate 'local' (Alpher \& Nash 1999).

8 The principal site adjacent to the settlement Kowanyama. The latter name is an English rendition of Yir-Yoront kawn yamar 'many waters', evidently used since the 1916 move of Mitchell River Mission from Trvpénvmvntvw, where the water sources had become saline. 


\section{THE GRAMMATICAL NATURE AND DEGREE OF SEMANTIC TRANSPARENCY OF THE NAMES}

A great many Yir-Yoront tract-names are transparent in meaning (as for example those in (1) and (2)); some, however, like Puyvl (Puyul), Mirtayrr and Kunqvmvl resist interpretation. As a very rough guess, simplex placenames with no other designation than the place itself constitute no more than 20 per cent of the total. For those whose meaning is interpretable, the meaning is usually elicitable in a straightforward manner from native speakers and often depicts an event in a myth connected with the tract. For some, however, only the first element can be given a ready gloss while the second cannot; examples are Therteyrr-Tha (therteyrr 'sandpaper fig'; example (3)) and Kawvn+Yumvlh (kawvn 'water').

All tract-names are proper nouns. Most of them contain more than one part, or constituent. Of these constituents, the first always belongs to the noun category. The second constituent can be a verb with tense-ending, or a noun. Tract-names with a noun as the second constituent take the form of noun-plus-noun or noun-plus-participle (a participle being a noun derived from a verb) compounds. Single-word tract-names, however, are not uncommon: Purr, Therlh, Puyvl, Mirtayrr, Kunqvmvl.

Tract-names whose second constituents are nouns often contain an overt LOCATIVE case-suffix (such are the +vmvntvw and + th of (1)). With common nouns, like yalq 'road, track', the locative suffix indicates 'at' or 'on' or sometimes 'to' the referent of the stem: $y a l q+a+l h$ 'on the road'. The unmarked, or citation form (the ABSOLUTIVE), yalq, can function as the subject of an intransitive verb or the object of a transitive verb and is the form normally given in response to a question of the type 'How do you say "road"?' With tract-names, on the other hand, the locative suffix appears to be frozen in place and to have lost the ability to contrast semantically with its absence. So it is, for example, with Wangrr-Yalqalh 'ghost-track', a noun-plus-noun compound with wangarr 'ghost', yalq 'track, road', and the locative suffix $+a+l h$; the corresponding form with no locative suffix, wangarr-yalq, is understood as a common noun, 'ghost's track', and not as a tract-name.'

It is likewise with tract-names whose last element is a participle: Larr-Low+Pannan 'Crying-Place', with larr 'place', low 'crying' (a noun), pann 'crying' (a participle; low+pann 'crying' is a participial phrase), and the locative suffix $+a+n$. Single-word tract-names continuing a locative form of a noun include items like Pirrmvrr, naming a place where trees of the species yo-pirmarr (coffee bush, Breynia oblongifolia) are abundant. Since elicitation of pirmvrr as the locative or ergative of the tree name pirmarr can be difficult to impossible, the placename Pirmvrr counts as an archaism. ${ }^{10}$ In other names, like Puyvl, there is an element (here $l$ ) that could be interpreted as a locative suffix, but no independent attestation of the putative stem (here *puy; i.e. puy is not recorded as an ordinary word whose meaning can

\footnotetext{
Proto Paman, from which Yir-Yoront has descended, distinguished an Ergative case, with both subject-of-transitive-verb and instrumental functions, from a locative case. The suffixes that marked the former all had the vowel * $u$, as in ${ }^{*} l u$, *ngku, *nytju, and others; those that marked the latter had * $a$, as in $* l a,{ }^{*} n g k a, * n y t j a$, etc. Yir-Yoront has lost the final vowels of the earlier Proto Paman, and hence a form like +lh continues both *nytju and "nytja. I am calling this form 'locative' in this presentation; elsewhere (e.g. Alpher 1991) I call it 'Ergative'. The $+a$ preceding the ending $+l h$ in $y a l q+a+l h$ is the THEMATIC vOWEL; see Alpher (1991:11 and 1999).
}

10 Nouns that inflect according to the pattern (Absolutive, Ergative) kanharr, kanhvrr 'crocodile', ngunyan, ngunyvn 'waves' regularly continue ancestral trisyllables, but this pattern is losing ground to simple suffixation. 
connect in any way with the tract $P u y v l)$. And there are tract-names, typically doubling as the common-noun names of animal species, which contain no suffix: Ngar-Manl (Rutland Plains Station homestead; 'catfish' as a common noun), Yoq-Minh-Mor ('jabiru tree' as a common noun: yoq 'tree', minh-mor 'jabiru').

A tract-name, whether its final element is a tensed verb or a noun (with or without locative ending), is used as follows: the citation-form means 'at' or 'to' the place: Puyvl 'at Puyul'; 'to' or 'towards' the place is the citation-form plus the Allative case-ending + tıyı w: Puyvl+uyuw 'towards Puyul'; 'from' the place is the citation-form plus the Ablative postposition ngorvm: Puyvl ngorvm 'from Puyul'. A sample of usage in context is the following:

$\begin{array}{lll}I & \text { pal thalvnh, Puyvl+uyuw. } \\ \text { there hither returned (place)+ALLATIVE }\end{array}$

'[They] were coming back this way, towards Puyul.'

Ngethn oylt, artm athan ngethn oylt nhinvnh, Puyvl.
we there mother my we there stayed (place)
'We, my mother and I, were staying there, at Puyul.'

There is evidence of a historical drift towards the locative marking of the citation-forms of tract-names in recent times: as time passes, more and more tract-names contain a recognisable locative suffix. Lauriston Sharp (pers. comm.) recorded one site as Minh-Tholhth Warrch 'Ritually Potent Bird' (minh-tholhth '(little) bird', warrch 'bad, ritually potent'). I recorded the name of the same site in 1966 as Minh-Tholhth-Wirrchir, with wirrch $+i+r$ the locative of 'bad'. The form with locative suffix evidently once had contrastive value as 'at' the place, as opposed to the citation-form, used for example (6 [1933 usage]) as the subject of a verbless predicate. The possibility of a case contrast of this kind (a meaningful difference between Minh-Tholhth-Warrch and Minh-Tholhth-Wirrchir) is evidently now lost. ${ }^{11}$

1933: Minh-Tholhth-Warrch, larr ngerr-yap.
1966: Minh-Tholhth-Wirrchir, larr ngerr-yap.
(place)
'Minh-Tholhth-Warrch is a good place.'

Yir-Yoront forms new lexical items primarily by compounding. The most frequent type of nominal compound is that of an unstressed noun followed by a stressed one (the hyphen as a notational device indicates this stress pattern). With names of plant and animal species, the unstressed element is a generic one and the stressed one a specific: minh-lalpm 'wallaby', minh-mirtin 'possum', minh-purrq 'bandicoot', etc., where minh is the generic for most furred animals, as well as reptiles and birds. Similarly, for fish the generic is ngart, or ngar- in context: ngar-kurr 'barramundi', ngar-marq 'diamond-scaled mullet', etc. With life-form terms, the generic is normally inseparable from the specific. ${ }^{12}$

\footnotetext{
1 Tract-names do occur as subjects of transitive verbs, in such sentences as 'Place X makes me sick', 'Place $Y$ makes me homesick (for some other place)'. When used thus, the name occurs in its citation-form.

12 In compound nouns of this type (the phrasal type, with the second element bearing the main stress), a case-ending can appear on the first element rather than on the second (or endings can appear on both
} 
The generic term for 'place' at its most general is larr. It has an ancient heritage in the Pama-Nyungan language family, with cognates like Warlpiri rdaku and Pintupi taku 'trench', and Diyari rdaku 'sandhill', and possibly Kala Lagaw Ya (Western Torres Straits Islands) laaga 'island', as well as numerous cognates meaning 'place' in Cape York languages; in Paman languages it continues a form reconstructible as "taakurr. Larr in Yir-Yoront is very polysemous (it has many distinct but related senses): 1. place, site, tract, estate; 2. spot, campsite; 3. terrain, country, land, zone, domain, distance; 4. ground, earth, soil, dirt; 5. ground as opposed to air or water; 6. substance, stuff; 7. time; 8. day, daylight; 9. period of day or history; 10. occasion, event; 11 . story; 12. custom, style, fashion; 13. season; 14. weather; 15 . condition of an entity; 16. world, cosmos. Larr is, however, used as a generic in rather few compound tract-names - an example being Larr-Low+Pannan 'Crying Place'.

A more popular generic for tract-names is pin, also highly polysemous: 1 . ear; 2 . generic for ear-shaped things; 3. ear as seat of intelligence and attention; 4. leaf of a plant; 5 . hair; 6. vulva; 7. site, place; 8 . home-place, country. The metaphor relating the last two of these senses to the first is probably that of concentric circles, as suggested by the cartilage of the ear and as represented pictorially in the art of Aborigines of the Centre. ${ }^{13}$ As a generic pin is usable freely with most tract-names: Pin-Ngar-Manl (Rutland Plains Station homestead), PinMarrcha, etc. Unlike the generics of life-form terms, however, pin in this usage is freely omissible: Ngar-Manl, Marrcha.

\section{GRAMMATICAL ARCHAISMS}

The grammatically archaic tract-names to which the title of this paper makes reference are among those whose last element is a verb with a tense ending. ${ }^{14}$ Examples containing no archaisms are Thum + Tharrarr ('heats up'), with thum 'fire' and tharrarr 'rises, does', and Par+Thayl ('burns the head') with par 'head' and thayl 'burns'. The tense-endings in these forms are the Nonpast $+r r$ and the Nonpast $+l$ respectively. They are the regular contemporary Nonpast endings for verbs of certain categories, the RR and $L$ conjugations, respectively.

The marking of Nonpast tense for three of the other conjugations of contemporary Yir-Yoront, the $\mathrm{NH}$, the $\mathrm{LH}$, and the Deponent-L, is zero, i.e. the absence of a suffix: respectively thur 'laughs', parrng 'blows', than 'stands'. There is good comparative evidence,

elements): kalq 'spear', Ergative kalqalh; kal-kow 'barb of spear', Ergative kalvlh-kow; kawn 'water', Ergative kowolh; kawn-wil 'salt water', Ergative kowlh-wila (or kawn-wila(h)); minh 'animal', Ergative minhal; minh-thaml 'animal foot', Ergative minhvl-thamarr. No other form of splitting of compounds occurs (without resulting in the loss of the item's lexical identity). For compounds that name an animal or plant species (note that a compound like kawn-wil 'salt water' consists, like biological names, of a generic and a specific), splitting by case-endings has not been recorded: minh-lalpm 'wallaby', Ergative minh-lalpalh; minh-purrq 'bandicoot', Ergative minh-purrqa.

13 Yir-Yoront pin continues Proto Paman *pina, with attestations in Cape York meaning 'ear' or 'leaf'. Outside of the Paman subfamily, Yuwaalaaray has bina 'ear'. But the connection of ear to place recurs with the Proto Pama-Maric etymon *yampa, continued as (for example) Umpila yampa 'ear', Yaraikana yampa 'leaf', and Bidjara yamba 'camp, humpy, place, time'.

14 The noun-like use of clauses with finite verbs is more general in the language, as in yoq-themrr+payl 'cockatoo-eats-it tree' (red ash); see Alpher (1991:72) for a brief discussion in context. 
however, that verbs of these categories once marked their Nonpast with a suffix, $+m$. This evidence comes from Yirrk-Mel, in forms like thanvm 'stands', nhinvm 'sits'.

Tract-names whose last element is a verb of one of these conjugations also mark that verb's tense, if it is Nonpast, with $+m$. Such are Pulpal+Thanvm 'cotton-tree stands', Tholprr+Thanvm 'stands [up to the chin] [in water]', and Minh-Kerrqel+Thanvm 'hawk stands'. It is evident that the tract-names retain a form of the verb that has been eliminated from the rest of the language. The elimination of $+m$ as a productive Nonpast ending was a matter of grammatical change (dealt with at length in Alpher 1999) and not sound-change. This is to say that it was not a matter of a shift in pronunciation: at no time did forms like thanvm become unpronounceable. ${ }^{15}$

Contemporary verbs of the $\mathrm{L}$ and $\mathrm{RR}$ conjugations mark their Past tense with a zero suffix: $y e$ 'cut', tha 'rose, went up, did'. But the evidence is strong that these once marked the Past with a suffix, $+r$; this suffix originated as ${ }^{*} n t V^{16}$ and continues as $+t$ in Yirrk-Mel yakat 'cut', and as $+n t$ in Kokapér yakánt 'cut'. Its loss in Yir-Yoront was, like that of $+m$, a matter of grammatical change and not sound-change (Alpher 1999). And tract-names with a final Past-tense verb of the relevant conjugation retain the $+r$ : Then $+Y a+r$ 'cut the penis' and possibly also $\mathrm{Ngaml}+\mathrm{Tha}+\mathrm{r}$ 'star rose'.

Some of the relevant tracts, like Tholprr+Thanvm and Then+Yar, are in the territory of people who formerly spoke Yirrk-Mel and now speak Yir-Yoront. It could be argued that these site-names simply continue the Yirrk-Mel form unchanged and do not constitute archaic Yir-Yoront. Consistent with this position is the fact that the vowel of yar 'cut' in the tract-name has failed to undergo a specifically Yir-Yoront change to the $e$ of the ordinary Yir-Yoront verb ye 'cut'. In favour of the archaism interpretation, however, are (i) that some of the names in question are from territory that has always been Yir-Yoront in language; (ii) that tract-names are almost always translated from language to language and almost never demonstrably borrowed, and all Yir-Yoront tract-names from the territory in question are distinctively Yir-Yoront in phonological form and not Yirrk-Mel (as, for example, Kowlh-Yalqalh whose $l h$ and $q$ identify it as Yir-Yoront, where Yirrk-Mel would have the corresponding th and $k$, respectively); and (iii) that the vocalism in a form like yar can perfectly well be regarded as a further archaism.

\section{DO COGNATE PLACENAME SETS REVEAL ANYTHING ABOUT PRIOR OCCUPATION OF THE PLACES NAMED?}

Evidence that land occupation continues from ancient times has enormous relevance in contemporary Native Title deliberations, and it is tempting to see cognate placename sets as providing such evidence. In this regard, however, data like these need to be approached with extreme caution. Compound words, for example, do not necessarily continue as compounds

15 Other tract-names in $m$ exist to whose second element no contemporary ordinary verb corresponds exactly. Examples are Lorrql+anvm, Pernt+anvm, Yum +anvm. It is clear for various reasons that these names have two constituents. One reason is that sequences of vowels like $a \ldots a$ in successive syllables, such as in Lorrql + anvm, do not occur in single-word common nouns. Another reason is that polysyllabic words in final $m$ are rare among common nouns. It is possible that the tanvm parts of these forms continue *than $+m$ 'stands' in changed form, or continues some other verb now lost. There is at present no compelling evidence for this putative history, however.

16 The ' $\mathrm{V}$ ' indicates a vowel of unknown quality whose probable presence is inferable from Yir-Yoront data (Alpher 1999). 
from a single ancestral compound. Clearly, the parts continue as cognates, but it is possible and even quite likely that the placenames are compounded independently in the two languages according to similar grammatical rules, to form names that translate one another. So evidence of this kind falls short of forcing a conclusion that (for example) the speakers of a language ancestral to Yir-Yoront, Yirrk-Mel and Kokapér frequented the places cited in (1-3), respectively, calling them *Tipanhtha, *Taarrcha-Manungka, *Thitithirr-Thaaki. The same caution holds for names freely formed under other grammatical constructions.

The case for continuation of a single placename from the protolanguage of the people who lived there is more compelling with sets of single-word placenames that are both (i) cognate but sound different - the more different, the more convincing - and (ii) without evident designation other than the place itself. Such might be Yirrk-Mel Mitathrr, Yir-Yoront Mirtayrr and Yirrk-Mel Kunkvmal, Yir-Yoront Kunqvmvl. As these tracts are in Yirrk-Mel country, however, and it is possible for Yir-Yoront speakers to adopt the name and shape it to their sound system and to apparent regularity of correspondence ("correspondence mimicry"; see Alpher and Nash 1999), even these examples fall short of being conclusive: it is conceivable that these places came to be recognised as Places (to be named) after the languages had diverged.

It is nonetheless possible that sets of cognate placenames will turn up that fairly unequivocally indicate prior occupation by speakers of the protolanguage before its differentiation. Because such a situation is plausible and because near-examples are known at present (see above), I think intensive research is likely to be successful. Such findings would be of enormous weight in considerations where continuity of residence and tenure is at issue.

\section{REFERENCES}

Alpher, Barry, 1991, Yir-Yoront Lexicon: sketch and dictionary of an Australian language. Berlin: Mouton de Gruyter.

- 1999, The origin of ablaut as a grammatical process in Yir-Yoront. MS.

Alpher, Barry and David Nash, 1999, Lexical replacement and cognate equilibrium in Australia. Australian Journal of Linguistics 19.1:5-56.

Hale, Kenneth, 1964, Classification of Northern Paman languages, Cape York Peninsula, Australia: a research report. Oceanic Linguistics 3:248-265.

- 1976a, Phonological developments in particular Northern Paman languages. In Sutton, ed., 1976:7-40.

- 1976b, Phonological developments in a Northern Paman language: Uradhi. In Sutton, ed., 1976:41-49.

— 1976c, Wik reflections of Middle Paman phonology. In Sutton, ed., 1976:50-60.

Sharp, R. Lauriston, 1934a, The social organization of the Yir-Yoront tribe, Cape York Peninsula. Oceania 4:404 431.

- 1934b, Ritual life and economics of the Yir-Yoront of Cape York Peninsula. Oceania 5:481-501. 
- 1937, The social anthropology of a totemic system in North Queensland, Australia. PhD dissertation, Harvard University.

- 1958, People without politics. In V.F. Ray, ed., Systems of Political Control and Bureaucracy in Human Societies, 1-8. Seattle: American Ethnological Society.

Sinnamon, Vivian and John Taylor, 1978, Summary of fieldwork, Kowanyama. Australian Institute of Aboriginal Studies Newsletter, New Series, 10:34-73.

Sutton, Peter, ed., 1976, Languages of Cape York (RRS 6). Canberra: Australian Institute of Aboriginal Studies.

- 1998, Native Title and the Descent of Rights. Perth: National Native Title Tribunal. 


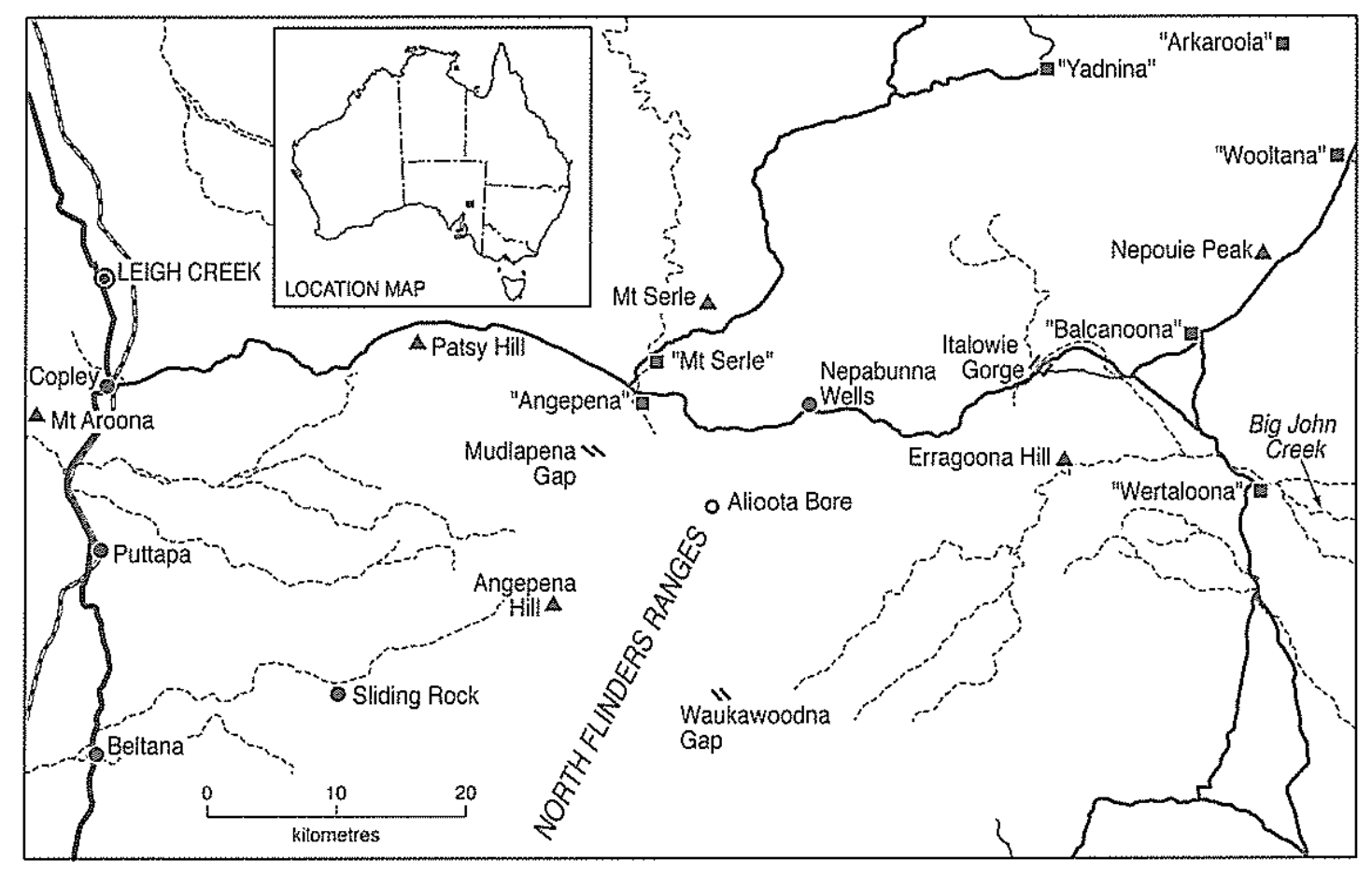

Map 1: The Northern Flinders Ranges 